\title{
Estadística del Servicio de Esterilidad del Hospital "San José" - Bogotá
}

\author{
Doctor J. Luna ll ribe
}

Como esbozo de estadística del trabajo ejecutado por el Departamento de Esterilidad del Hospital San José, desde agosto 4 de 1952, presentamos el re sultado práctico que el estudio de las historias clinicas permite obtener.

Consultaron un total de 99 mujeres, de las cuales 55 (55\%) acusaban es. terilidad primaria y $4+(45 \%)$ esterilidad secundaria.

Despues del plan rutinario de estudios se llego a la conclusión de que la posible causa de esterilidad era de origen

A) Tивано en veintisiete casos; divididos en nueve de estenosis y diecio cho de impermeabilidad u oclusión tubaria. De estos casos fueron tratados cinco, con persuflacion durante el acto quirurgico en el que se practico una salpingo plastia; controles pesteriores certilican el exito de la intervención, ya que a la insuflacion uterotubaria se aprecia permeabilidad en cuatro de ellos, y un fra caso en el cual no se obtuvo paso del gas en los controles.

B) Cervical en cuatro casos, en tres de ellos se encontró una cervicitis rebelde; de estas pacientes está una en control y dos han abandonado el estudio. En el otro caso se encontró una estrechez del conducto cervical y fue tratado quirúrgicamente.

(i) Ovánco Endochino en seis casos; se llegi al diagnostico de ovaritis es. cleropuistica, y se practico en cuatro de ellos la resección cunciforme de los ova rios; los otros dos están listos para su tratamiento quirúrgico; de los casos inter venides des se han perdido de vista. En dos cases se hallaron deficiencias hor monales y se instituyo, el tratamiento médico adecuado. También fueron aten didos des cases de atresia de los órganos genitales, uno de les cuales está actual mente en control y el otro se perdio de vista

D) En cuanto a Factor Marido se tropieza con la poca colaboración, ya que de noventa y nueve pacientes femeninas, únicamente diecinueve maridos 
asistieron a la consulta, y de éstos la mayoría (por no decir la totalidad) concurrieron una sola vez. De ellos, cinco se pueden considerar como causa de esterilidad, pues se encontraban alteraciones al estudio del espermograma. En los demás maridos (14) que concurrieron, no se hallo ninguna alteracion que explique la esterilidda de la pareja.

Como otros datos de interés, obtuvimos

19-En dos pacientes estudiadas, no se encontró causa urganica ni funcio nal que explicara su esterilidad; afortunadamente sus maridos concurrieron a consulta y se establecio, en uno de ellos una azoospermia ! el antecedente de irradiaciones vesicales; y en el otro alteraciones en el spermograma que pueden explicar dicha esterilidad.

29-Se han perdido de vista (nos referimos a paciente- que no asisten a control por lo menos desde mayo del presente año) treinta y nueve casos, lo que correspondería a un 42.8\%; entre ellos se cuentan algunos qu los casos tratados para su probable causa de esterilidad. lo cual nos impide verificar el éxito que estos tratamientos pudieran haber tenides.

30-Permanecen en estudio cuarenta y ocho casos.

40- Unicamente podemos informar con certeza de un cass de embarazo, va que la paciente concurre periódicamente a los controles; sin embargo se nos ha informado de otra paciente que está en las mismas condiciones, y estamos esperando que concurra a una cita que se le envio para establecer la verdad de la información. 